\title{
A IMAGINAÇÃO GEOGRÁFICA E AS REPRESENTAÇÕES DOS LUGARES SAGRADOS
}

\author{
"Da minha aldeia vejo quanto da terra se pode ver no Universo \\ Por isso a minha aldeia é tão grande como outra terra qualquer \\ Porque eu sou do tamanho do que vejo \\ E não, do tamanho de minha altura..."
}

Fernando Pessoa

- otÁVIO JOSÉ LEMOS COSTA

RESUMO: NO ÂMBITO DA GEOGRAFIA, É EXPRESSIVA A QUANTIDADE DE ESTUDIOSOS QUE VEM SE DEDICANDO À INVESTIGAÇÃO DA OCORRENAIIA DE PAISAGENS, LUGARES E TERRITÓRIOS NOS QUAIS O SAGRADO INCITA UMA MANIFESTAÇ̃̃̃O. AO DISCUTIRMOS 0

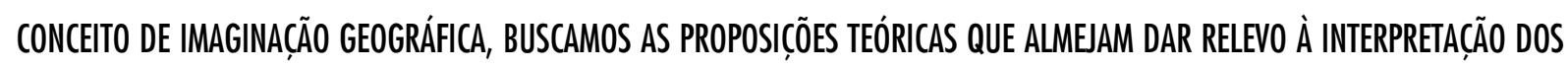
FENÔMENOS SÓCIO-ESPACIAIS QUER ESTEAM ASSOCIADOS A UMA PERSPECTIVA DA NATUREZA, QUER ESTEAM ATRELADOS ÀS PRÁtICAS SIMBÓLICAS CUJOS ElEMENTOS DISCURSIVOS INDICAM UM PROCESSO QUE ENVOLVE A PRODUCÃ̃ DE PAISAGENS CULTURASS, DE LUGARES OU TERRITÓRIOS E TERRITORIALIDADES SIMBÓLLCAS PELAS QUE UMA CONSTRUCÃ̃o IDENTITÁRIA É SEMPRE

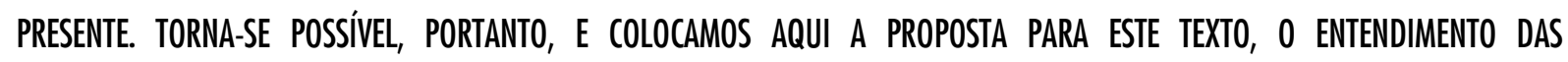
REPRESENTAC̄õES DO SAGRAdO CONTEXTUALZZANDO NA SEARA dA IMAGINAC̣̃̃ GEOGRÁFICA.

PALAVRAS-CHAVES: IMAGINACÃO GEOGRÁFICA. LUGAR. SAGRADO

Compreender as diversas formas de na obra de Edward Said - O Orientalismo - na qual percepção dos lugares, das paisagens ou qualquer se verifica uma ampliação geográfica do seu objeto manifestação que indique a ação do homem, de estudo. Aqui o autor nos diz que o Oriente vai resulta conforme Claval (2002) da sua capacidade além das formas simbólicas representativas como imaginativa. Tal fato é exemplarmente apresentado as areias escaldantes do deserto, o sol, entre 
outros, mas também se constitui como uma experiência histórica e também como uma ambição geográfica (SAID, 2007). Mostra-nos também Said, que a imaginação de um império e seus efeitos no processo de colonização se tornavam o objetivo principal, retratando assim, o olhar colonial que recobria a imaginação geográfica pela qual o império circunscrevia fronteiras, essas sendo construídas artificialmente.

O conceito de imaginação geográfica firma-se nas proposiçõos teóricas que almejam dar relevo à interpretação dos fenômenos sócioespaciais quer estejam associados a uma perspectiva da natureza, quer estejam atrelados às práticas simbólicas cujos elementos discursivos indicam um processo que envolve a produção de paisagens culturais, de lugares ou territórios e territorialidades simbólicas pelas quais uma construção identitária é sempre presente. Torna-se possível, portanto, e colocamos aqui a proposta para este texto, o entendimento das representações do sagrado contextualizando na seara da imaginação geográfica.

Assim, a nossa compreensão do espaço sagrado inclui os atributos da imaginação enquanto projetos simbólicos e utópicos (MERRIFIELD, 1993). Uma imaginação geográfica que nos faça enxergar uma espacialidade em termos mais amplos, realizando uma prospecção nos significados que compõem as narrativas através das múltiplas dimensões do espaço, uma vez que essas dimensões, entre elas o econômico, o político e o social mantêm estreitas relações com o simbólico (CORRÊEA, 2012). A observação de um espaço sagrado na ótica de uma imaginação geográfica nos permite adentrarmos na estrutura das narrativas daqueles que constroem o sagrado. A história dos personagens, sua relação com o lugar sagrado, os diálogos entre eles, as formas simbólicas espaciais constituem o cerne dessa imaginação que se relaciona com outros temas que transcendam esses ambientes locais do individuo.

No âmbito da geografia, é expressiva a quantidade de estudiosos que vem se dedicando à investigação da ocorrência de paisagens, lugares e territórios nos quais o sagrado incita uma manifestação. A proliferação de um pluralismo religioso, por exemplo, em decorrência de uma nova onda de migrantes, sobretudo na Europa ocidental, provenientes do Leste Europeu e Norte da África, vem fazendo com que a religião, nas últimas décadas, se torne algo instigante e proponha uma nova agenda para a geografia. Poderíamos pensar numa imaginação geográfica agora inserida nas mudanças que ocorrem em um contexto global pelas quais novas circunstâncias ensejam vários caminhos para a investigação (KONG, 2010). Assim, novas religiões, novas diásporas, novos conflitos, novas territorialidades têm direcionado percepções para uma geografia que permite outras abordagens enfocando os estudos da religião.

Nos vários campos investigativos, bem como no âmbito da Geografia, afirma Daniels (2010, p. 182) que "o lugar e o estatuto da imaginação é moldado pela posição e pela pressão de um conjunto de conceitos contrapontuais". Tais conceitos podem ser expressos pela razão, 
objetividade, experiência, moralidade e materialidade. Neste sentido, a imaginação nos é apresentada como algo que se situa entre os domínios do factual e ficcional, entre a objetividade e a subjetividade ou ainda entre o real e o representacional. Esses binômios constituem a retórica que permeou várias investigações embasadas na fascinante "terra incognitae", presente nos corações e mentes do homem (LOWENTHAL, 1961) e a relação entre o mundo exterior e as imagens em nossas mentes. A percepção dessas imagens, o olhar direcionado para as paisagens e lugares nem sempre coincidem com aspectos de suas geografias, uma vez que aqueles aspectos são recônditos, obscuros e desconsiderados pela geografia.

Constitui, portanto, um salutar exercício para nós, geógrafos, observarmos as microgeografias contidas nas paisagens e lugares. Agindo dessa maneira aprendemos a decompor formas, sentidos e ruídos, que se escondem em seus interiores naquilo enfaticamente apontado por Merleau-Ponty (1999, p. 285) como sendo algo que "antes de ser um espetáculo objetivo, a qualidade deixa-se reconhecer por um tipo de comportamento que visa sua essência". Poderíamos pensar também que a imaginação geográfica se aproximaria daquilo que LOWENTHAL (1961) sugere em um dos seus ensaios acerca da variabilidade do pensamento geográfico, o que ele iria conceituar como "geografias pessoais ou particulares".

\section{AS REPRESENTAÇÕES DO SAGRADO}

A temática das representações sociais se apresenta como um amplo campo de pesquisas no contexto das ciências humanas. Balizaremos nosso entendimento sobre as mesmas vinculando à perspectiva do sagrado a partir das concepções desenvolvidas por Durkheim (1996), Jodelet (1991), Hall (1997), Sá (1998), Moscovici (1978, 2000), uma vez que estes autores apresentam interpretações que convergem para o entendimento de fenômenos sociais. Assim, procuramos aliar uma compreensão sobre a imaginação geográfica, acrescentando as análises sobre as representações substantivadas com a contribuição da geografia humanista, que enfatiza aspectos que envolvem o sentimento e a emoção (ROWNTREE, 1995).

Enfatizando o conceito de representação na compreensão dos lugares sagrados, ressaltamos a sua importância na análise sócio-espacial, uma vez que o papel das representações tem sido essencial para o entendimento do comportamento humano (BAILY, 1984), sendo, portanto parte essencial de um processo pelo qual o indivíduo ou a coletividade atribuem um sentido a seus lugares de vida. Com afirma Almeida (2008, p. 315) "uma característica do estudo geográfico é ser ele uma representação do mundo". Neste contexto, o lugar e suas respectivas características do sagrado são envolvidos por representações e que a linguagem dos signos e imagens oferece um suporte que lhes representa simbolicamente, resultando em uma geografia que comporta subjetividades, sentimentos e experiências para o conhecimento do lugar. 
O conceito de representação social foi proposto inicialmente por Emile Durkheim quando propõe a idéia de representação coletiva, afirmando que a vida social é toda feita de representações. $\mathrm{O}$ conceito de representação social em Durkheim (1996) foi empregado na elaboração de uma teoria da religião, da magia e do pensamento mítico, argumentando que esses fenômenos coletivos não podem ser explicados em termos de indivíduos, pois é produto de uma coletividade. No seu livro "As Formas Elementares da Vida Religiosa", o estudo dos fenômenos religiosos torna-se um objeto central de análise.

No âmbito do estudo das religiões, Émile Durkheim centralizou sua pesquisa em torno dos povos primitivos, procurando observar o fenômeno religioso em seu substrato mais puro, salientando que "as religiões primitivas não permitem apenas destacar os elementos constitutivos da religião, além de terem também a grande vantagem de facilitar sua explicação, posto que nela os fatos são mais simples e as relações entre os fatos são também mais evidentes" (DURKHEIM， 1996). Durkheim observa o fenômeno religioso como um primado da consciência coletiva em detrimento de seus aspectos morais e materiais. As representações compreendem, nesse caso, um conjunto de idéias que, juntamente com as práticas rituais irão compor um sistema que procura exprimir o mundo. Ao surgirem as sociedades, as representações são produzidas e os indivíduos que compõem essa coletividade sentem-se ligados uns aos outros pelo simples fato de terem uma fé comum. Para Durkheim, os sistemas de linguagem, ou seja, os conceitos, as categorias do julgamento, em outras palavras, as representações que se fazem sobre o mundo são em grande parte de seus estudos dedicados a responder ao enigma de como produzem-se essas idéias, essas crenças sejam elas religiosas ou não.

Moscovici (2005), por sua vez, argumenta que a teoria das representações, tem sua origem na seara da Sociologia e da Antropologia. Entretanto, sugere uma ênfase na vertente da Psicologia Social, salientando que, o conceito de representações sociais se refere a um conjunto de proposições e explicações criadas no mundo cotidiano, ou seja, as representações comportam um conjunto de ideias e crenças que necessitam ser descritos e explicados. Portanto, sendo considerada como uma forma sociológica da Psicologia Social, Moscovici irá desenvolver o estudo das representações socais dentro de uma metodologia na qual criticava os pressupostos positivistas e funcionalistas das demais teorias que não explicavam a realidade. As representações sociais para Moscovici são consideradas como entidades quase tangíveis, presentes na realidade, que se manifestam em palavras, objetos e em relações sociais, constituindo um conjunto dinâmico cujo status é de uma produção de comportamentos e de relações com o meio ambiente (MOSCOVICI, 1978). Assim, são entendidas como uma constituição de um objeto e expressão do sujeito, estando relacionadas com um modo particular de compreender e se comunicar. 
Consoante ao pensamento de Moscovici, Denise Jodelet (1991), destaca que as representações sociais são, por um lado, sistemas que registram nossa relação com o mundo exterior, orientando e organizando condutas. Por outro, interferem nos processos, diversificando a difusão e assimilação dos conhecimentos. Para Jodelet, trata-se de fenômenos múltiplos que se observam e se estudam aos níveis da complexidade, sejam elas individuais ou coletivas. Destaca ainda que a especificidade das representações sociais caracteriza-se por uma intensidade e fluidez de trocas e comunicações, constituindo um objeto de estudo legítimo e extremamente relevante enquanto categoria analítica que atua em uma determinada realidade social.

Na concepção de Stuart Hall (1997), o conceito de representação tem ocupado um novo e importante lugar no estudo da cultura, sendo uma parte essencial do processo pelo qual o significado é produzido e modificado pelos membros de uma cultura, envolvendo o uso dos signos, da linguagem e das imagens, que oferece suporte ou representa as coisas. Segundo Hall $(1997$, p. 17)

"existe no cerne do processo de significação da cultura, dois sistemas de representações. O primeiro é capaz de nos fornecer o significado das palavras, através da construção de um jogo de correspondências ou cadeia de equivalências entre coisas, pessoas, objetos, eventos, etc. e nossos sistemas de conceitos, ou seja, os mapas conceituais. O segundo sistema associa-se à construção de um conjunto de correspondências entre nosso mapa conceitual e um conjunto de signos, arranjados ou organizados para várias linguagens as quais representam esses conceitos."

A teoria das representações sociais, considerando a compreensão dos significados é apresentada por Hall (1997), que indica a existência de três grandes correntes as quais definem a natureza dos signos: a reflexiva, a construcionista e a intencionalista. Entre elas, consideramos a abordagem construcionista a que melhor se identifica com as representações sociais, pois, nos explica Hall que não devemos confundir o mundo material, enquanto fenômenos apreendidos sensorialmente, no qual as coisas e as pessoas existem, em função de suas práticas simbólicas, mas considerar os significados como algo construído a partir da experiência. Sob a ótica da representação, é o mundo não-material que conduz o significado ou ainda como afirma Berger e Luckmann (1996, p. 54), "a realidade cotidiana não é cheia de objetivações, mas constantemente envolvida por intenções subjetivas".

A relação entre a teoria das representações e a geografia torna-se mais relevante a partir dos estudos da geografia humanista, que teve como base filosófica a fenomenologia e o 
existencialismo, ressaltando a contribuição de David Lowenthal (1982), que enseja novos parâmetros epistemológicos, enfatizando o caráter subjetivo da explicação da paisagem. A paisagem e o lugar ganham destaque nas análises da geografia cultural, sobretudo em sua vertente humanista.

Com o aporte teórico das representações sociais, vinculado à natureza dos lugares sagrados, é estabelecido um nível mediador entre o real e as dimensões simbólicas, nas quais o caráter religioso dos lugares está sublimado pela intersecção do sagrado com o secular, conferindo, portanto, uma tênue separação entre as forças seculares e o sagrado (HENKEL, 2005).

Considerar como pertinente as representações sociais em uma abordagem geográfica, é reabilitar ao mesmo tempo o sujeito, a sua experiência e o sentido que ele incorpora ao espaço (GUMUCHIAN, 1991). Nesse contexto, a abordagem humanista nos permite ler e interpretar o espaço, sua organização e funcionamento. As investigações mais recentes sobre as representações sociais na seara da geografia têm obtido um amplo alcance, sugerindo temáticas e possíveis aplicações para compreender o espaço. Além do debate epistemológico, o geógrafo não se exime das influências do espaço mental, da construção individual e social que influencia cada um de nossos atos. Tal postura vai ao encontro do pensamento de Moscovici (2000, p. 30) ao afirmar que "nós percebemos o mundo tal como é e todas as nossas percepções, idéias e atribuições são respostas a estímulos do ambiente físico ou quase-físico que nós vivemos". Assim, as representações do espaço ocorrem na dimensão da vida cotidiana e na interpretação de Sá (2004): o processo de gênese das representações tem lugar nas mesmas circunstâncias, e ao mesmo tempo, em que se manifestam.

Entendendo ser a religião um conjunto de representações construído por um sistema solidário de crenças e de práticas relativas às coisas sagradas (DURKHEIM, 1996), a discussão que se firma naquilo que concerne às representações dos lugares sagrados, nos conduz a uma observação fundamental: a marca permanente de uma realidade subjetiva, ou seja, os lugares sagrados são espaços vividos cujas representações indicam os sentidos que os indivíduos dão a esses lugares. Considerando também que a essência da geografia é a compreensão do homem e sua relação com o espaço, relação esta que se objetiva através da construção dos territórios, das paisagens e dos lugares, o estudo das representações privilegia, portanto, o espaço como objeto. Ao enfocarmos os lugares sagrados como objeto de análise, enfatizamos o fenômeno das representações como elemento que integra a subjetividade e a imaginação do sujeito naquilo que concerne a uma percepção de uma dada espacialidade.

Dessa forma os lugares sagrados são moldados através do tempo, recebendo do homem marcas indeléveis que se apresentam enquanto formas visuais. Estas formas visuais não são apenas representações imaginárias, mas sim representações de um tipo muito específico de lugar. Como nos lembra Gil Filho (2002, p. 263) 
"uma geografia do sagrado não é a consideração pura e simples das espacialidades dos objetos e fenômenos sagrados em, por conseguinte, de seu caráter locacional; mas sim, sua matriz relacional. A geografia do sagrado estaria muito mais afeta à rede de relações em torno da experiência do sagrado do que propriamente às molduras perenes de um espaço coisificado."

Um sistema de relações está presente nos lugares sagrados nos quais as representações sociais se associam aos elementos do lugar, do social e do cultural, o que seria no entender de Bourdieu (2001) a configuração de um espaço social que se apresenta como uma "topologia social $^{\prime \prime}$ na medida em que representa um mundo social com múltiplas dimensões construído na base de princípios de diferenciações ou de distribuição constituídos pelo conjunto das propriedades que atuam no universo social considerado. As representações dos lugares sagrados indicam uma construção operada por diversos grupos sociais e que resultam em diversas significações. Nesse caso, as representações compreendem um conjunto de idéias que irão compor uma espacialidade particular que procura exprimir mundo.

A compreensão que se faz de uma geografia das representações tem esteio em uma geografia do conhecimento simbólico. Gil Filho (2005, p. 57) nos indica quatro instâncias analíticas para uma geografia das representações as quais nos ajudam a estabelecer o entendimento dos lugares sagrados. Na primeira instância, ele se refere à espacialidade fenomênica que é apresentada através de nossos instrumentos perceptivos imediatos. Aqui entenderíamos os lugares sagrados a partir das formas espaciais simbólicas existentes, sejam elas construídas pelo homem ou modeladas pela natureza. A segunda instância trata-se da apreensão conceitual, pela qual concebemos as formas espaciais por seus predicados e como reconhecemos sua estrutura simbólica. Nesta instância, poderíamos dizer que está circunscrito o cerne do conceito das representações, uma vez que a função das representações é tornar familiar o não-familiar numa dinâmica em que os objetos e eventos são reconhecidos e compreendidos. $\mathrm{Na}$ terceira instância, o autor irá admitir as representações sociais enquanto fenômenos espaciais per se, nesse caso, as representações sociais são as expressões da espacialidade social.

O lugar sagrado aciona no homem uma variedade de sentimentos, assumindo ideias de grandeza e pertencimento. Os santuários e os lugares de peregrinação, por exemplo, estão carregados de um simbolismo cosmológico. Portanto, as representações que se fazem desses lugares, indicam leituras ou maneira de observar o mundo de acordo com culturas e mentalidades. Há nas representações dos lugares sagrados uma dimensão cósmica na qual as diversas simbologias se associam intimamente ao espírito humano 
dando origem a diversas espacialidades. A quarta instância, apontada por Gil Filho se define pelo tratamento das representações sociais como base conceitual e analítica de uma geografia do conhecimento engendrada pela dialética entre universo consensual e universo reificado. $\mathrm{O}$ trânsito entre esses dois universos irá ampliar a discussão das Representações Sociais e que na visão de Moscovici (2000, p. 49) assim são definidas

"no universo consensual, a sociedade é uma criação visível, continua, permeada com sentido de finalidade, possuindo uma voz humana com a existência humana e agindo tanto como reagindo, como ser humano. Em outras palavras, o ser humano é aqui, a medida de todas asa coisas. No universo reificado, a sociedade é transformada em um sistema de entidades sólidas, básicas, invariáveis, que são indiferentes à individualidade $\mathrm{e}$ não possuem identidade."

Sendo, portanto, o universo consensual como local onde o indivíduo está presente o tempo inteiro e cada um participa com o saber que possui, exercendo livremente suas opiniões. Tudo nesse universo pode ser compreendido com base no saber social adquirido e compartilhado pela coletividade. No universo reificado temos um mundo mais formal. No lugar da individualidade, existe um sistema de classes e papéis a serem exercidos. Neste universo as pessoas são vistas como desiguais, significando assim que cada indivíduo só pode participar de acordo com sua competência, ou seja, exercendo apenas o papel que the cabe.

Se o universo consensual é o local da familiaridade, onde o coletivo acolhe determinados fatos e o incorpora como parte de sua identidade ou de seu cotidiano, poderíamos afirmar que os lugares sagrados se associam a uma imaginação geográfica, nos quais são expressões desse universo consensual, uma vez que as formas simbólicas espaciais, os rituais, a experiência com o sagrado podem ser considerados como estruturas familiares para aqueles que vivenciam esses lugares. Entretanto, para uma parte da população que não vivencia a festa, os rituais ou qualquer determinação associada ao sagrado, esses lugares poderiam representar um universo reificado.

A relação entre as representações sociais e os lugares sagrados é construída a partir de práticas sociais no espaço vivido pelos sujeitos. No contexto, os lugares sagrados vêm a ser o objeto de representação o qual é percebido e que está relacionado diretamente às formas e aos fenômenos imediatos. Buscaria, portanto, uma objetivação da espacialidade, ou como salienta Gil Filho (2005, p. 57) "demonstra como os atores sociais individuais e coletivos marcam a existência de determinada realidade espacial". Caberia dizer que, as representações sociais enquanto fenômenos espaciais comportam o domínio das 
operações simbólicas, redefinindo espacialidades a partir das associações entre o objetivo e o subjetivo, necessitando serem entendidas a partir de contextos específicos que as engendram bem como no âmbito das relações sociais do cotidiano.

Assim, nos lugares sagrados, pode-se perceber a interação humana e neste sentido Moscovici (2000, p. 40) irá salientar que "sempre e em todo lugar quando encontramos pessoas e coisas e nos familiarizamos com elas tais representações estão presentes". Nos lugares sagrados vamos encontrar também as manifestações de sentimentos e comportamentos que devem ser analisados a partir da compreensão da conduta dos fiéis e que definem uma espacialidade, caracterizando o que Jovchelovitch (1998, p. 74) qualifica na teoria das representações sociais como um espaço potencial, dotado de símbolos e imagens. Os símbolos aí presentes constituem, portanto, um espaço potencial que pressupõe a capacidade de evocar a presença apesar da ausência, uma vez que eles podem significar outra coisa. Para o devoto que visita um lugar sagrado, as representações de formas simbólicas são automaticamente criadas, uma nova realidade é construída. Neste sentido, se cria também um novo olhar para o objeto representado, construindo então uma nova realidade para aquela já existente.

Considerando que a essência da geografia é a compreensão do homem e sua relação com o espaço, relação esta que se objetiva através da construção dos territórios, das paisagens e dos lugares, o estudo das representações privilegia, portanto, o espaço como objeto. Ao enfocarmos os lugares sagrados como objeto de análise, enfatizamos o fenômeno das representações como elemento que integra a subjetividade e a imaginação do sujeito naquilo que concerne a uma percepção de uma dada espacialidade.

Entretanto, é ampliada a perspectiva para o exercício da imaginação geográfica no contexto das representações, tal caminho se delineia pelo interesse da "extra-oficialidade" do sagrado (KONG, 2010) no qual as práticas religiosas têm direcionado sua investigação. As práticas banais, práticas do cotidiano, práticas de uma sacralidade cívica como nos aponta Rosendahl (2001, p. 21) ao ressaltar que "existe um conjunto de crenças, símbolos e cerimônias que servem para evocar um poder que emana do povo, sem possuir referências a poderes sobrenaturais". Assim, a imaginação geográfica permite a compreensão de práticas espaciais que supera aquilo que já conhecemos ou nos faz surpreender com algo que já estamos habituados a ver.

Entendemos, portanto, que as questões relacionadas a uma imaginação geográfica e sua relação com as representações do sagrado se ampliam ao incluirmos assuntos que transcendem o lugar-comum. Tal imaginação revela-se, por exemplo, ao refletirmos sobre um lugar sagrado, representado pelo Santuário de Nossa Senhora Rainha do Sertão, localizado em Quixadá-CE, instalado no topo alto de um morro dominando a vasta planície sertaneja, sugerindo uma íntima relação entre as feições geomórficas e a religião (COSTA, 2010). A própria localização do 
santuário nos remete à Fickeler (1999), que enaltece os cultos da montanha, pois os mesmos atingem sua eficácia máxima na paisagem quando levam à construção de estruturas religiosas, seja em forma de capela, cruzes, portais, túmulos ou mosteiros.

A organização espacial dos lugares sagrados anuncia, portanto, uma tênue relação entre os valores e as representações, delineando práticas que são desenvolvidas pelos sujeitos, os quais estabelecem ligações de familiaridade e afetividade. Assim, quando nos referimos a uma geografia das representações associadas aos espaços sagrados, buscamos em Bailly (1984) a compreensão de que as imagens mentais evocam representações que utilizam informações conceituais e experiências perceptivas, portanto, são representações que se definem tanto pela memória quanto pela percepção, possuindo ainda duas funções: uma, referencial, para reconstruir as percepções e outra, elaborativa, para organizar as novas relações ou experiências anteriores.

Diante do lugar sagrado, o sujeito se depara com um conjunto de elementos simbólicos - templos, roteiros devocionais, rituais, imagens contextualizando um privilegiado e íntimo espaço para aquele que crê. Os objetos presentes nos lugares sagrados, sejam eles desde os mais simples aos mais elaborados, quer seja uma pequena cruz à beira da estrada ou uma imponente catedral efetuam, portanto, um caráter simbólico ou ainda estão referenciados em uma instância de espacialidades a qual se contextualiza o sujeito. Logo, trata-se de apreender as representações sociais que se atualizam através das narrativas presentes nas romarias, na devoção aos santos, nas hierópolis, enfim nas práticas e crenças que induzem a experiência do vivido, pois o lugar sagrado é um espaço que abre possibilidades diversas para se instaurarem as representações as quais permitem ao fiel exercer no espaço e tempo sagrado suas percepções de mundo.

Essa relação do sujeito com os elementos simbólicos associados ao sagrado procura um enquadramento de tal forma que devemos pensar na perspectiva de uma filosofia humanística. Tal propositura rejeita, portanto, a separação entre o sujeito e o objeto (HUBBARD et. al. 2002), questionando o "estar no mundo" através de uma análise do cotidiano e a capacidade do sujeito experimentar e criar seus próprios mundos. A discussão que se faz neste momento reflete a dimensão na qual o expediente das narrativas se insere na busca da interpretação dos fatos, procurando uma aproximação mais fidedigna daqueles envolvidos em suas contextualizações específicas.

Muito embora Abric (2005) nos alerte para uma parte da representação que não é verbalizada ou não expressada porque o indivíduo não quer torná-la pública e que ele conceitua como zona muda, temos a consciência de que a grande maioria das apreensões que constituem as narrativas dos sujeitos indica as suas representações da realidade e, como tal está repleta de significados e reinterpretações. Como nos mostra Sá (1998, p. 22) "os fenômenos da representação social são mais complexos do que os 
objetos que construímos a partir deles". Na afirmativa do autor, podemos perceber que ao trabalharmos com os sujeitos na tentativa de obter elementos que classifiquem o real, há sempre uma simplificação quando passamos do fenômeno ao objeto de pesquisa. Essa simplificação implicaria a construção do objeto da pesquisa e estaria embutida na formação de uma representação social.

Portanto, discutir uma imaginação geográfica a respeito dos lugares sagrados nos conduz a uma postura que se repalda na mudança do olhar para o objeto empírico. Como afirma Cosgrove (1979, p. 43), "os geógrafos têm recentemente mudado de uma pueril postura teórica e quantitativa da organização humana do espaço para uma reanálise das dimensões qualitativas pelas quais envolvem a experiência dos lugares e suas singularidades" Sendo assim, compreendemos que a imaginação geográfica é parte de uma experiência investigativa a partir da qual nos é permitido lançar um olhar, por exemplo, sobre os lugares e paisagens do sagrado, trilhando abordagens que reconheçam a perspectiva da narrativa em um contexto fenomenológico.

O exercício da imaginação geográfica no contexto de uma articulação entre o sujeito e o objeto confronta-se com determinadas situações como supressões de episódios, negação de etapas ou ênfase em idéias, situações estas que possuem muitos significados, pois, apesar da simplificação, a

pesquisa com representações sociais não é uma tarefa muito simples, uma vez que as representações quando estão associadas ao ambiente de pensamento da vida cotidiana poderão englobar outros elementos inerentes ao sujeito ou aos grupos envolvidos em contextos sócio-culturais. Nesse sentido, é preciso estar atento, sobretudo, com relação ao sujeito investigado. É possível e salutar discutir com os sujeitos visando conhecer melhor o perfil das narrativas no cerne das representações. Consideramos um exercício interessante, pois é capaz de explorar compreensões e sentimentos antes não percebidos e que nos conduz a fatos esclarecedores no processo investigativo.

Portanto, podemos pensar o lugar sagrado, evocando a imaginação geográfica no contexto das representações. Dessa maneira, refletimos criticamente sobre o problema da objetivação em termos dos valores subjetivos. (PROCTOR, 1998). Transgredir a fronteira da objetivação e atingir os parâmetros de uma subjetividade tornase, dessa forma, a tarefa do geógrafo preocupado em compreender a realidade através de significados. Nos lugares sagrados, certamente as fronteiras entre a objetividade e a subjetividade são tênues e estimulam a diversidade da imaginação geográfica, oferecendo um amplo campo de investigação para aqueles que buscam a interpretação dos espaços sagrados.

Representações Sociais: uma teoria sem Fronteiras. Rio de Janeiro Ed. Museu da República, 2005

ABRIC, Jean Claude. A Zona Muda das Representaçôes. In: Oliveira Denise C. de e Campos, Pedro Humberto Faria. (org.) 
ALMEIDA, Maria Geralda de. Uma Leitura Etnogeográfica do Brasil Sertanejo. In: Ângelo Serpa. (org.) Espaços Culturais: Vivências Imaginações e Representações. Salvador: EDUFBA, 2008.

BAILY, Antoine. Les Concepts de la Geographie Humaine. Paris

Masson, 1984

BERGER, Peter L. e LUCKMANN, Thomas. A Construção Social da Realidade. Petrópolis: Ed. Vozes, 1996.

CLAVAL, Paul. A Volta da Geografia Cultural. Mercator. Revista de Geografia da UFC. Fortaleza, Ano 01, n. 1, 2002.

CORRÊA, Roberto Lobato. Espaço e Simbolismo. In. CASTRO, I E.; GOMES, P. C. C. e CORREA, R. L. (org.) Olhares Geográficos Modos de Ver e Viver o Espaço. Rio de Janeiro: Bertrand Brasil, 2012

COSGROVE, Denis. John Ruskin and the geographical imagination. Geographical Review, vol. 69, nº 1 pp. 43-62, 1979

COSTA, Otávio José Lemos. Hierópolis: o significado dos lugares sagrados no sertão cearense. In: ROSENDAHL, Z. (org.) Trilhas do sagrado. Rio de Janeiro: EdUERJ, 2010

DANIELS, Stephen. Geographical Imagination. Transactions of British Geographers. Vol. 36, p. 182-187,2011

DURKHEIM, Emile. As Formas Elementares da Vida Religiosa. São Paulo: Editora Martins Fontes, 1996.

FICKELER, Paul. Questões Fundamentais na Geografia da Religião. Espaço e Cultura. Rio de Janeiro. NEPEC/EDUERJ, nº. 7, p.7-35/ jun. de 1999.

GIL FILHO, Sylvio Fausto. Por uma Geografia do Sagrado. In MENDONÇ, F. e KOZEL, Salete. (orgs.) Elementos de Epistemologia da Geografia Contemporânea. Curitiba: Editora UFPR 2002.

Sylvio Fausto. Geografia Cultural e o Primado das Representações. Espaço e Cultura, no. 3, dez pp.51-59, Rio de Janeiro, UERJ/NEPEC, 2005.

GUMUCHIAN, Hervé. De la Perception aux Representations em géographie In: Representations et Armágenagement du Territoire Paris: Antropos-Difusion Econômica, 1991

HALL, Stuart. (org.) The Work of Representation. In: Representation Cultural. Representations and Sygnifing Practices. London: Sage Publications, 1997

HENKEL, Reinhard. Geography of Religion: redescovering a subdiscipline. Hrvatski Geografsky Glasnik 67/1, 5-25, 2005
HUBBARD, Phil et al. Thinking Geografically. Space, Theory and Contemporary Human Geography. London/New Yor. Continuum, 2002.

JODELET, Denise. Representations Sociales: un domaine en expansion. In: JODELET, D. (org.) Les Representations Sociales. Paris: PUF, 1991

JOVCHELOVITCH, Sandra. Vivendo a Vida com os Outros: Intersubjetividade, espaço público e representações sociais. In: GUARESCHI, Pedrinho \& JOVCHELOVITCH, Sandra. (orgs.). Textos em Representações Sociais, Petrópolis,RJ: Vozes, 1998. KONG, Lily. Global Shifts, theoretical shifts: Changing geographies of religion. Progress in Geography Human. Vol. 34(6) pp. 755-776, 2010

LOWENTHAL, David. Geography, experience and imagination towards a geographical epistemology. Annals of the Association of American Geographers. Vol. 51, p. 241-260, 1961

David. Geografia, experiencia e imaginação: em direção a uma epistemologia geográfica. In: Christofletti, Antonio (org.). Perspectivas da Geografia. São Paulo: DIFEL, 1982.

MERLEAU-PONTY, Maurice. Fenomenologia da Percepção. São Paulo: Martins Fontes, 1999

MERRIFIELD, Andrew. Place and Space: a Lefebvrian Reconcialition. Transactions of British Geographers. Vol. 18, p. 516531,1993

MOSCOVICI, Serge. Representações Sociais. Petrópolis: Vozes, 2000

Serge. A Representação Social da Psicanálise. Rio de Janeiro: Zahar Editores, 1978

PROCTOR, James. Ethics in geography: giving moral form to the geographical imagination. Area, vol. 30, n. 1, pp. 8-18, 1998.

ROSENDAHL, Zeny. Espaço, Política e Religião. Religião Identidade e Território. In: Rosendahl, Z.; CORREA, R. L. (Org.) Rio de Janeiro: EdUERJ, 2001

SÁ. Celso Pereira de. A Construção do Objeto de Pesquisa em Representações Sociais. Rio de Janeiro: EDUERJ, 1998

SAID, Edward. Orientalismo. O Oriente como Invenção do Ocidente. São Paulo: Companhia de Letras, 2007.

Celso Pereira de. Representações Sociais; o conceito e o estado atual da teoria. In: SPINK, Mary Jane (org.) O Conhecimento no Cotidiano. São Paulo: Brasiliense, 2004.

\section{GEOGRAPHICAL IMAGINATION AND REPRESENTATIONS OF SACRED PLACES}

Abstratc: Within Geography, it is expressive the number of scholars that has been dedicated to investigating the occurrence of landscapes, places and territories where the sacred incites a demonstration. In discussing the concept of geographical imagination, we seek the theoretical propositions that aim to highlight the interpretation of socio-spatial phenomena are associated with either a 
perspective of nature, whether tied to symbolic practices whose elements indicate a discursive process that involves the production of landscapes cultural places or territories and territoriality in which a symbolic identity construction is always present. It is possible, therefore, here and put the proposal to this text, the understanding of the sacred representations contextualizing the harvest of the geographical imagination.

KEYWORDS: GEOGRAPHICAL IMAGINATION, PLACE, SACRED 